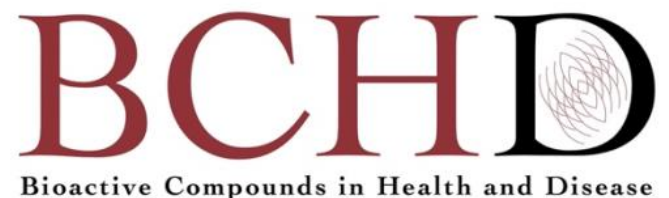

\title{
Study of the effect of gallic acid and cold plasma on the levels of inflammatory factors and antioxidants in the serum sample of subjects with type 2 diabetes mellitus
}

\author{
Danik Martirosyan', Hamid Ghomi², Mohammad Reza Ashoori ${ }^{3}$, Alireza Rezaeinezhad², \\ Afsaneh Seyed Mikaeili ${ }^{4}$, Fahimeh Jahanbakhshi ${ }^{2}$ and Hossein Mirmiranpour ${ }^{5}$
}

${ }^{1}$ Functional Food Center, Functional Food Institute, Dallas, TX, USA; ${ }^{2}$ Laser and Plasma Research Institute, Shahid Beheshti University, G. C., Tehran, Iran; ${ }^{3}$ Department of Laboratory Sciences, School of Allied Medical Sciences, Zanjan University of Medical Sciences, Zanjan, Iran; ${ }^{4}$ Department of Molecular and Cellular Sciences, Faculty of Advanced Sciences and Technology, Islamic Azad University, Pharmaceutical Sciences Branch, Tehran, Iran; ${ }^{5}$ Endocrinology and Metabolism Research Center (EMRC), Valiasr Hospital, School of Medicine, Tehran University of Medical Science, Tehran, Iran

Corresponding author: Hossein Mirmiranpour, MD, PhD, Endocrinology and Metabolism Research Center (EMRC), Valiasr Hospital, School of Medicine, Tehran University of Medical Science, Tehran, Iran

Submission Date: July 16 ${ }^{\text {th }}, 2021$; Acceptance Date: August 13 ${ }^{\text {th }}, 2021$; Publication Date: August $26^{\text {th }}, 2021$

Please cite this as: Martirosyan D., Ghomi H., Ashoori M.R., Rezaeinezhad A., Mikaeili A.S., Jahanbakhshi F., Mirmiranpour $\mathrm{H}$. Study of the effect of gallic acid and cold plasma on the levels of inflammatory factors and antioxidants in the serum sample of subjects with type 2 diabetes mellitus. Bioactive Compounds in Health and Disease 2021. 4(8): 167-179. DOI: https://www.doi.org/10.31989/bchd.v4i8.824

\section{ABSTRACT}

Background: Uncontrolled type 2 diabetes mellitus can have devastating consequences. The role of functional foods in controlling and even preventing diabetes mellitus is prominent, and adjunct therapies can help control some of the consequences of diabetes.

Objective: This study aimed to investigate whether gallic acid (as a functional food) and cold atmospheric plasma (as an adjunct therapy) influence the levels of some antioxidant enzymes, inflammatory factors, and the levels of an oxidizing agent and blood glucose.

Methods: In this study, 30 healthy individuals, as the control group, and 30 individuals with type 2 diabetes 


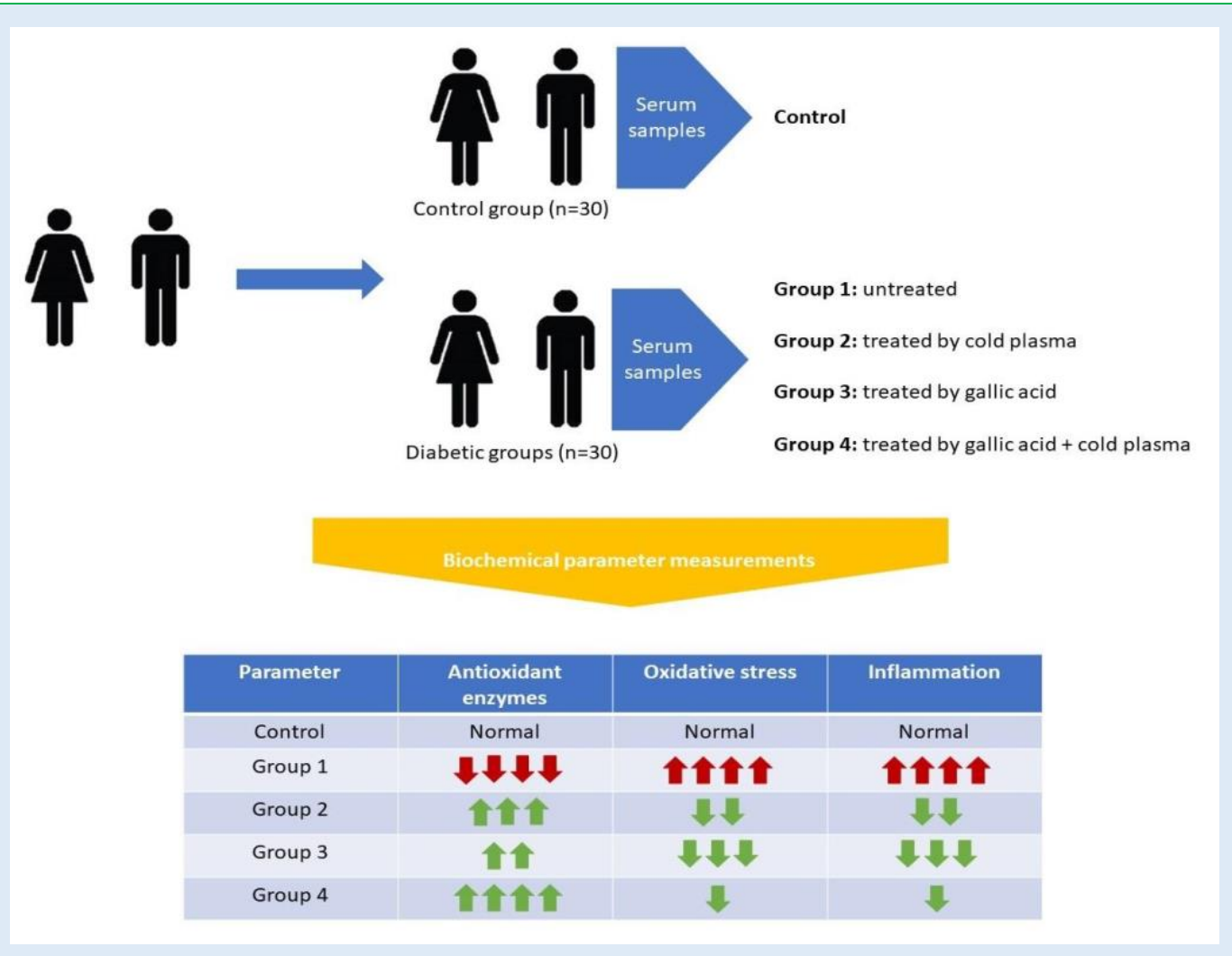

mellitus were selected. Samples of people with diabetes were examined before and after treatment with gallic acid and cold atmospheric plasma (cold argon plasma jet for 10 minutes). Levels of inflammatory factors (interleukin 2, 13 and NF-KB), antioxidants (glutathione reductase, paraoxonase, and lipoprotein lipase) as well as hydrogen peroxide and blood glucose, were assessed in untreated and treated diabetic groups and the control group according to kit instructions.

Results: A comparison of the results of the levels of inflammatory factors, antioxidants, blood glucose, and hydrogen peroxide showed a significant difference $(P$ value $<0.05)$ between the diabetic and control groups. Treatment of diabetic subjects with plasma and gallic acid showed a significant increase $(P$ value $<0.05)$ in glutathione reductase, paraoxonase, and NF-KB levels compared to the untreated diabetic group.

Conclusion: The results showed that concomitant use of gallic acid with plasma therapy, could be effective on NF$\mathrm{KB}$, glutathione reductase, and paraoxonase levels, yet the data suggest little or no effect. The results of the study showed that cold plasma treatment along with gallic acid supplementation can have a synergistic effect on the regulation of oxidative stress and inflammatory cytokine secretion in the patients with type 2 Diabetes mellitus.

Keywords: Diabetes mellitus, Cold plasma, Inflammatory factors, Gallic acid

CFFC 2021. This is an Open Access article distributed under the terms of the Creative Commons Attribution 4.0 License (http://creativecommons.org/licenses/by/4.0) 


\section{INTRODUCTION}

Diabetes mellitus (DM) is a metabolic disorder caused by a lack of insulin secretion or improper functioning of insulin in the body. In this disease, blood sugar levels rise, and the function of the body's organs is impaired. DM is divided into two main and important types: type $1 \mathrm{DM}$, which is caused by insufficient insulin secretion by the $\beta$-cells of the islets of Langerhans (in the pancreas), and type 2 DM, known as insulin-resistant diabetes, which is caused by improper functioning of insulin in the body [1]. Today, it may not be possible to prevent type $1 \mathrm{DM}$ (due to genetic and autoimmune factors islet $\beta$-cell destruction), but it is possible to prevent type $2 \mathrm{DM}$ [2]. In today's world, the prevalence of type $2 \mathrm{DM}$ is much higher than type 1 DM. The World Health Organization (WHO) estimates that by 2025, more than 250 million people worldwide will have type 2 DM [3]. In addition to genetic risk, factors such as lifestyle, obesity, and weight gain are involved in developing type 2 DM [4-5]. Apart from the role of genetics in the development of diabetes, other risk factors for diabetes can be controlled. Lack of control and management of DM leads to its proliferation. Cardiovascular disease, retinopathy, nephropathy, neuropathy, etc. are consequences of uncontrolled diabetes. Reactive oxygen species (ROS), oxidative stress and inflammatory factors caused by uncontrolled diabetes are involved in these pathologies.

Antioxidants are one of the most important biological molecules that protect the body against the dangers of endogenous and exogenous oxidants [6]. Singlet oxygen, superoxide anions, and hydrogen peroxide $\left(\mathrm{H}_{2} \mathrm{O}_{2}\right)$ are some of the well-known oxidants. Antioxidants help prevent the dangerous consequences of DM [7]. In recent decades, many studies have shown that through the consumption of functional foods in some fruits and foods, DM can be controlled and even prevented. Green tea and coffee are among the functional foods that are nutritionally important [8-9]. One of the most important functional compounds in green tea, which is also found in some plants and fruits such as pomegranate, is gallic acid (Figure 1). Chemically, gallic acid is a trihydroxybenzoic acid and is classified in the family of phenolic acids [10]. It has been shown that pomegranate reduces serum fasting glucose levels due to its functional compounds, such as gallic acid. Gallic acid has been widely used as a nutritional supplement and an additive. The anti-inflammatory, antioxidant, and anti-diabetic properties of gallic acid have been discussed in many studies. Studies have reported that gallic acid can be considered one of the most potent antioxidants in humans [11-12]. Another study showed that gallic acid could play an important role in improving glucose tolerance and triglyceride concentrations in obese mice [13]. The protective effects of gallic acid in type 2 diabetic rats can be due to decreased blood glucose, decreased lipid peroxides in the liver, increased plasma insulin, and hepatic antioxidant systems [14].

In recent years, research has identified a link between the physical sciences and the medical sciences. Plasma medicine is one of the most widely used medical sciences today. There are several types of plasma, and in modern medicine, hightemperature plasmas have been used to sterilize medical devices, and cold atmospheric pressure plasmas (CAP) have been used to treat some living tissues, such as the skin. Plasmas emit electromagnetic radiation, such as visible light and ultraviolet (UV) rays. It can be said that plasma has been used as an adjunct in the control and treatment 
of some diseases. In recent years, studies have been conducted on the effects of CAP and its role in the control and treatment of diseases [15-18]. Almost all studies have focused on dermatology and the treatment of skin diseases. Some of the consequences of uncontrolled diabetes are skin injuries and wounds, and plasma can be effective in treating this disease [19-20]. It has been reported that plasma therapy can have beneficial and positive effects on antioxidant enzymes [21]. In two previous studies, we also showed that plasma can affect the activity of antioxidant enzymes as well as the concentration of some minerals [22-23]. In this study, the effect of gallic acid as a functional food and the effect of CAP as an adjunct therapy on some inflammatory factors (such as interleukin-2 (IL-2), interleukin-13 (IL-13), nuclear factor kappa-lightchain-enhancer of activated B cells (NF-kB)), paraoxonase (PON), lipoprotein lipase (LPL), glutathione reductase (GR), glucose, and $\mathrm{H}_{2} \mathrm{O}_{2}$ were studied.

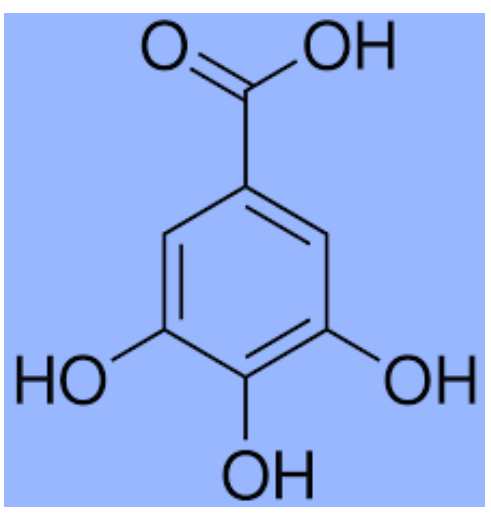

Figure 1. Chemical structure of gallic acid

\section{METHODS}

Gallic acid, as a trans isomer, was purchased from Sigma (Sigma-Aldrich, St. Louis, USA). Human glucose (with an intra- and inter-assay CV $<8 \%$ and $<10 \%$, respectively) and enzyme-linked immunosorbent assay (ELISA) kits were purchased from My BioSource Inc. (San Diego, CA 92195-3308, USA). The $\mathrm{H}_{2} \mathrm{O}_{2}$ assay kit was bought from Zell Bio (Zell Bio GmbH, Ulm, Germany). The colorimetric method was used to study changes in $\mathrm{H}_{2} \mathrm{O}_{2}$ levels. The study of $\mathrm{GR}, \mathrm{PON}$, and LPL changes was also investigated by colorimetric technique. ELISA method was used to assay changes in levels of IL-2, IL-13, and NF-KB. A Human ELISA assay kit was purchased from MyBioSource Inc. (San Diego, CA 92195-3308, USA) to study changes in NF-
KB. Assay kits for IL-2 and IL-13 were purchased from Diaclone (25020 Besancon Cedex, France).

Plasma Irradiation: The samples were treated for 600 seconds by an atmospheric pressure plasma jet (APPJ) device at a $10 \mathrm{~mm}$ distance from the jet nozzle (Figure 2). APPJ device consists of a Pyrex tube (L: $150 \mathrm{~mm}$, ID: $4 \mathrm{~mm}$, OD: $6 \mathrm{~mm}$ ) as a dielectric barrier, a copper rode ( $L: 30 \mathrm{~mm}, \mathrm{D}: 1 \mathrm{~mm}$ ) inserted in one end of the tube as the high voltage electrode, and a copper wire wrapped around the other end of the tube as a ground electrode. The argon plasma jet was generated by utilizing a $10 \mathrm{kHz}$ pulsed DC power supply with an amplitude up to $10.0 \mathrm{kV}$ and argon gas with a purity of $99.999 \%$ at a $31 \mathrm{~min}^{-1}$ flow rate. 


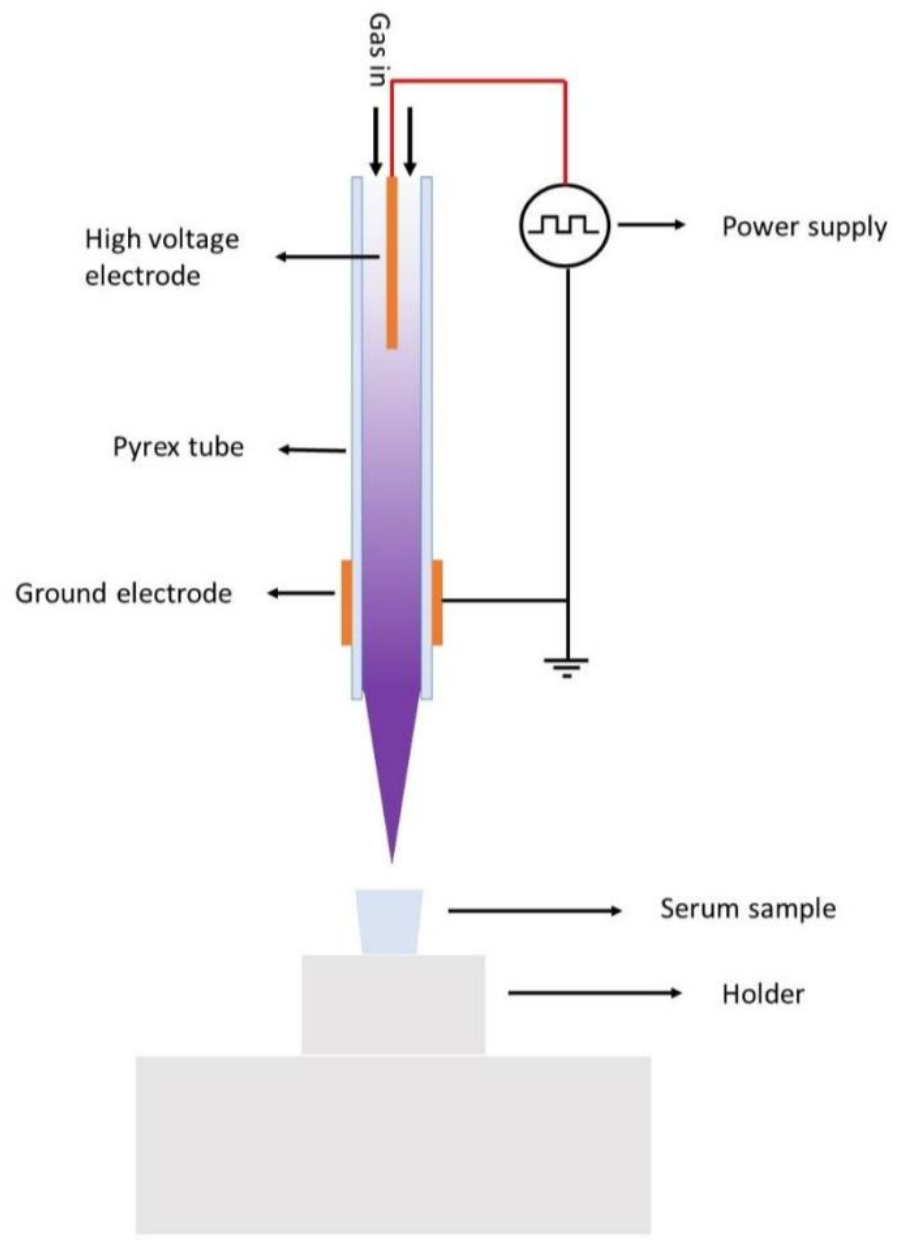

Figure 2. Samples exposed to atmospheric pressure plasma jet (APPJ)

Participants: In this investigation, 30 healthy control subjects and 30 volunteers with type 2 DM were chosen among the people referred to Vali-Asr medical laboratory in Tehran, Iran. Based on the WHO criteria, individuals with glycated hemoglobin (HbA1c) $\geq 6.5 \%$ or fasting plasma glucose $\geq 126 \mathrm{mg} / \mathrm{dL}$ were considered as diabetic. Blood samples were taken from all participants in the study. Serum isolated from samples of people with diabetes were divided into four groups. Changes in the levels of biochemical variables, described above, were determined in untreated diabetic serum samples (Group 1) and after samples treatment with CAP (Group 2). Then, the same subjects were treated with Gallic acid (at a dose of $40 \mathrm{mg} / \mathrm{kg}$ per day) for three months. After three months, blood samples were taken from them. Biochemical variables were measured in their serum samples (Group 3). After treating the samples with cold plasma, biochemical variables were examined (Group 4). That is, in group 4, the effects of both gallic acid and cold plasma on the samples were investigated. Written consent was obtained from all participants. During this research, the persons with type $2 \mathrm{DM}$ also took their main medication. A protocol of the study was accepted by the Ethics Board of Shahid Beheshti University, on June 20, 2020, with ID Approval: IR.SBU.REC.1399.050.

Sampling and General Features: Blood samples were taken from all study subjects following twelve hours 
of overnight fasting. Then, the blood samples were centrifuged ( $250 \mathrm{~g}$ for $10 \mathrm{~min}$ ) and the serums were separated from centrifuged specimens. The sera were used to assess the biochemical variables and antioxidant enzymes described earlier. After one day, samples were exposed to CAP and examined for a second time.

Statistical Analysis: The statistical analysis was carried out with the SPSS software (version 23, IBM, USA) for Windows. All outcomes have been reported as mean \pm standard deviation. The KolmogorovSmirnov test was used to analyze the normal distribution of data received from this study, and an independent-sample T-test was used to compare the data obtained from the general characteristics of all individuals. To compare the mean of data obtained from the study groups, the one-way ANOVA test was performed with a 0.05 significant level ( $P$ value < 0.05). Tukey post hoc was used (Tukey-HSD test) was applied.

\section{RESULTS}

Anthropometric Parameters: As previously mentioned, in this observational study, 30 subjects with type $2 \mathrm{DM}$ and 30 healthy, control subjects were randomly selected. In both groups, 50\% were male $(n=15)$, and $50 \%$ were female $(n=15)$. All participants were between 50 and 65 years old. Height, weight, and body mass index (BMI) were recorded in all participants in the study (Table 1). As shown in Table 1 , there was a significant difference $(P$ value $<0.05)$ in the mean BMI between controls and diabetics.

Table 1. Anthropometric data

\begin{tabular}{|cccc|}
\hline \multicolumn{1}{|c}{ Group } & $\begin{array}{c}\text { Control } \\
n=30\end{array}$ & $\begin{array}{c}\text { Diabetic } \\
n=30\end{array}$ & P value \\
\hline Parameters & $85.4 \pm 5.5$ & $82.8 \pm 5.0$ & 0.06 \\
\hline Weight $(\mathrm{Kg})$ & $166.3 \pm 5.8$ & $168.2 \pm 6.1$ & 0.23 \\
\hline Height $(\mathrm{Cm})$ & $30.1 \pm 3.0$ & $29.3 \pm 2.3$ & 0.02 \\
\hline BMI $\left(\mathrm{Kg} / \mathrm{m}^{2}\right)$ & & & \\
\hline
\end{tabular}

Data are given as mean \pm SD. P value $<0.05$ is significant. BMI, Body mass index

Biochemical Parameters: In the serum sample of the control group and diabetics, some important variables were measured. These biochemical variables included blood glucose, antioxidant enzymes ( $G R, P O N$, and $L P L)$, an oxidizing agent $\left(\mathrm{H}_{2} \mathrm{O}_{2}\right)$, and inflammatory agents (IL-2, IL-13, and NF$\mathrm{KB})$. Changes in the levels of biochemical variables were investigated in the serum samples of the control group and the serum samples of subjects with type 2 DM (groups 1 to 4). A comparison of the results of inflammatory factors (IL-2, IL-13, and NF-KB) between the control group and the four diabetic groups is shown in Figure 3 and Figure 4. A comparison of the results of other biochemical variables such as glucose, $\mathrm{H}_{2} \mathrm{O}_{2}$, and antioxidant parameters (GR, PON, and LPL) is shown in Table 2. As shown in Figures 3 and 4 as well as Table 2, there was a statistically significant difference ( $P$ value $<0.05)$ in the results of groups 1 to 4 compared to the control group. As shown in Figures 3 and 4 as well as Table 2, the results of the 
concentration of inflammatory agents in diabetic patients treated with gallic acid (as a functional food) as well as treated serum samples of these patients with CAP did not show a significant difference compared to the untreated diabetic group.

Table 2. Comparison between the levels of biochemical parameters in the control group with other groups

\begin{tabular}{|c|c|c|c|c|c|c|}
\hline \multirow{2}{*}{$\begin{array}{l}\text { Biochemical } \\
\text { parameters }\end{array}$} & \multicolumn{6}{|c|}{ Groups } \\
\hline & $\begin{array}{l}\text { Control } \\
(n=30)\end{array}$ & $\begin{array}{c}\text { Group } 1 \\
(n=30)\end{array}$ & $\begin{array}{c}\text { Group } 2 \\
(n=30)\end{array}$ & $\begin{array}{c}\text { Group } 3 \\
(n=30)\end{array}$ & $\begin{array}{c}\text { Group } 4 \\
(n=30)\end{array}$ & P value \\
\hline $\mathrm{GR}(\mathrm{mU} / \mathrm{ml})$ & $25.9 \pm 2.1$ & $14.4 \pm 1.6$ & $15.7 \pm 1.5$ & $16.63 \pm 1.60$ & $17.32 \pm 1.59$ & $<0.001$ \\
\hline PON (U/ml) & $183.2 \pm 6.8$ & $107.2 \pm 4.9$ & $111.2 \pm 4.9$ & $115.2 \pm 4.9$ & $117.23 \pm 4.9$ & $<0.001$ \\
\hline LPL (pg/ml) & $1403.5 \pm 45.9$ & $876.5 \pm 45.9$ & $888.9 \pm 45.7$ & $889.5 \pm 45.9$ & $891.03 \pm 44.1$ & $<0.001$ \\
\hline Glucose $(\mu \mathrm{g} / \mathrm{ml})$ & $211.4 \pm 20.1$ & $445.9 \pm 22.4$ & $443.3 \pm 19.8$ & $442.93 \pm 22.4$ & $441.9 \pm 22.4$ & $<0.001$ \\
\hline $\mathrm{H}_{2} \mathrm{O}_{2}(\mu \mathrm{M} / \mathrm{ml})$ & $237.6 \pm 18.6$ & $353.3 \pm 25.4$ & $340.8 \pm 15.1$ & $342.33 \pm 25.4$ & $338.3 \pm 25.4$ & $<0.001$ \\
\hline
\end{tabular}

Data are given as mean \pm SD.

Group1: Diabetic. Group 2: Diabetic + plasma. Group 3: Diabetic + Gallic acid. Group 4: Diabetic + Gallic acid + plasma. GR, glutathione reductase; PON, paraoxonase; LPL, lipoprotein lipase

The levels of changes in biochemical variables between serum samples of the diabetic group were investigated with the following conditions: untreated with gallic acid and plasma, treated with gallic acid, treated with plasma, and treated with plasma and gallic acid. To evaluate the impact of plasma and the effect of both plasma and gallic acid on the biochemical variables, a comparison of the results was done between the groups. Multiple comparisons were made by the Tukey HSD Post Hoc test (Table 3). A significant difference was observed in the comparison of biochemical variables in the group treated with both gallic acid and plasma with the untreated samples. There was no significant difference between the results of inflammatory factors, blood glucose, and $\mathrm{H}_{2} \mathrm{O}_{2}$ in the CAP-treated diabetic group compared to the untreated diabetic group. When comparing the results of inflammatory factors, blood glucose, antioxidants, as well as $\mathrm{H}_{2} \mathrm{O}_{2}$ in the treated diabetic group with gallic acid with the untreated samples, except for $P O N$ and $L P L$, no significant difference was observed. Comparison of GR, PON, and NF-KB between the diabetic group treated with gallic acid and plasma with the untreated diabetic group showed a significant difference. When comparing other variables between the diabetic group treated with both plasma and gallic acid and the untreated diabetic group, no significant difference was observed. 


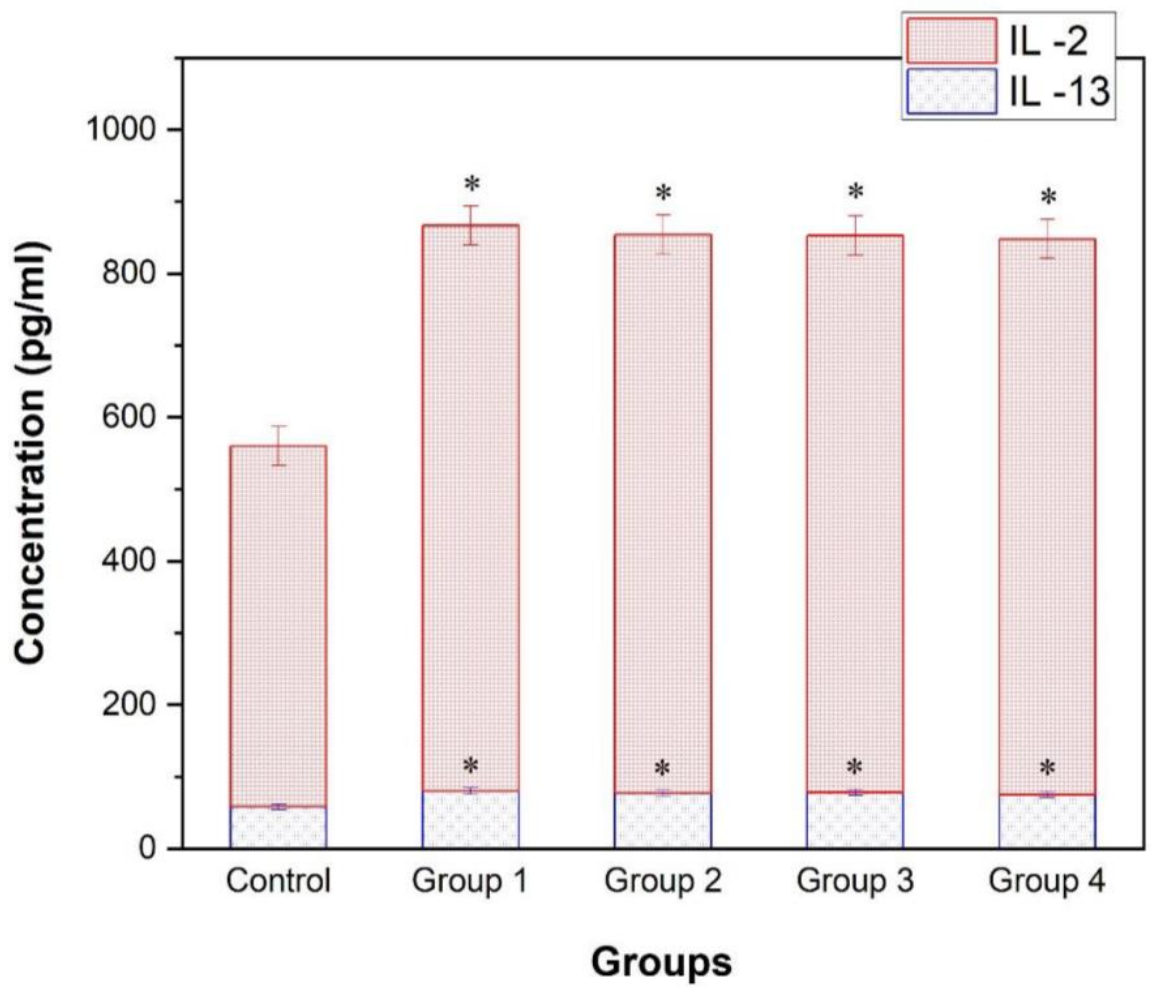

Figure 3. Changes in the IL-2 and IL-3 levels in the control and diabetic groups (in different conditions). * Significances of data comparing diabetic samples vs. the control group (P value $<0.05$ ). Group 1: diabetic. Group 2: diabetic + plasma. Group 3: diabetic + gallic acid and Group 4: diabetic + gallic acid + plasma.

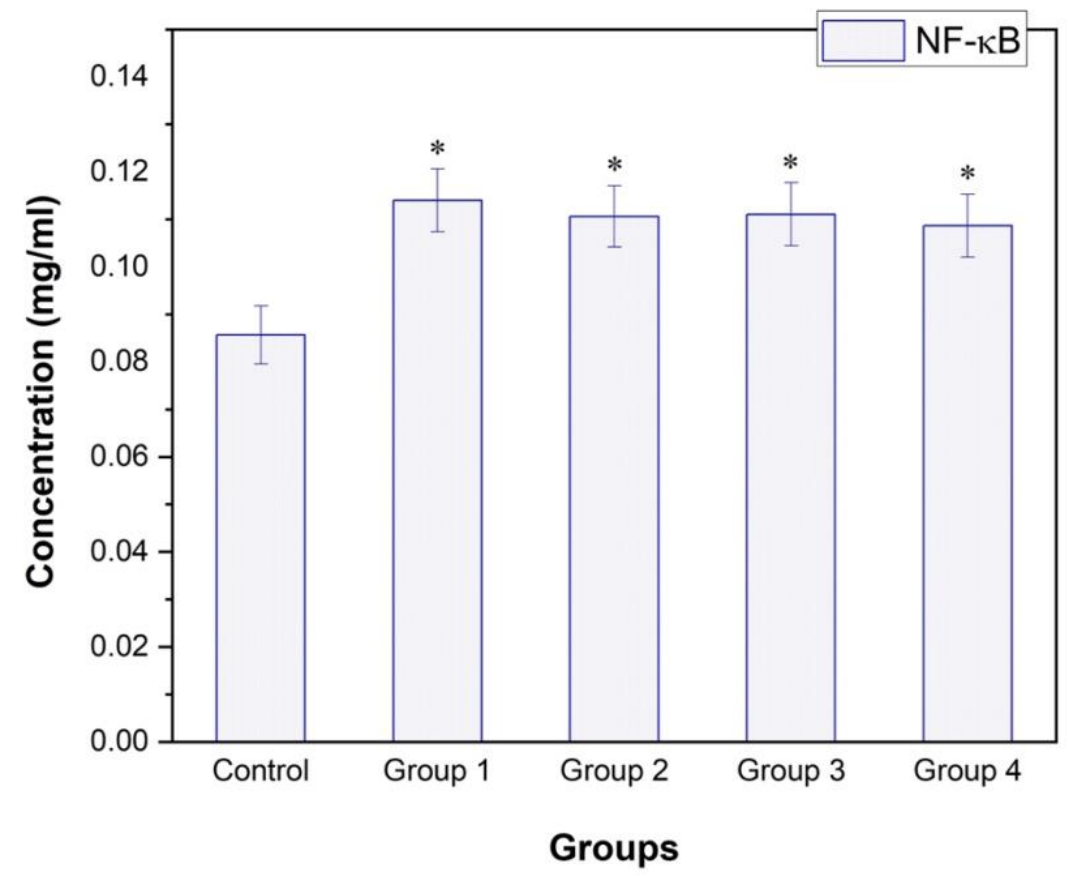

Figure 4. Changes in the serum NF-KB levels in the control and diabetic groups (in different conditions). * Significances of data comparing diabetic samples vs. the control group (P value $<0.05)$. Group 1: diabetic. Group 2: diabetic + plasma. Group 3: diabetic + gallic acid and Group 4: diabetic + gallic acid + plasma. 
Table 3. Multiple comparisons between the levels of biochemical parameters between the groups

\begin{tabular}{|c|c|c|c|c|c|c|c|c|c|}
\hline Group & & $\begin{array}{c}\text { GR } \\
(\mathrm{mU} / \mathrm{ml})\end{array}$ & $\begin{array}{c}\text { PON } \\
(\mathrm{U} / \mathrm{ml})\end{array}$ & $\begin{array}{c}\text { LPL } \\
(\mathrm{pg} / \mathrm{ml})\end{array}$ & $\begin{array}{c}\text { IL-2 } \\
(\mathrm{pg} / \mathrm{ml})\end{array}$ & $\begin{array}{c}\text { IL-13 } \\
(\mathrm{pg} / \mathrm{ml})\end{array}$ & $\begin{array}{c}\text { NF-KB } \\
(\mathrm{mg} / \mathrm{ml})\end{array}$ & $\begin{array}{l}\text { Glucose } \\
(\mu \mathrm{g} / \mathrm{ml})\end{array}$ & $\begin{array}{c}\mathrm{H}_{2} \mathrm{O}_{2} \\
(\mu \mathrm{M} / \mathrm{ml})\end{array}$ \\
\hline \multirow[t]{3}{*}{ Group 1} & Group 2 & 0.008 & 0.022 & 0.88 & 0.49 & 0.49 & 0.26 & 0.98 & 0.20 \\
\hline & Group 3 & 0.0002 & $<0.0001$ & 0.83 & 0.58 & 0.58 & 0.43 & 0.98 & 0.54 \\
\hline & Group 4 & $<0.0001$ & $<0.0001$ & 0.76 & 0.27 & 0.24 & 0.01 & 0.96 & 0.12 \\
\hline \multirow[t]{3}{*}{ Group 2} & Group 1 & 0.008 & 0.022 & 0.88 & 0.49 & 0.49 & 0.26 & 0.98 & 0.20 \\
\hline & Group 3 & 0.19 & 0.013 & 0.99 & 0.99 & 0.99 & 0.99 & 0.99 & 0.99 \\
\hline & Group 4 & 0.0090 & 0.001 & 0.99 & 0.99 & 0.99 & 0.73 & 0.99 & 0.98 \\
\hline \multirow[t]{3}{*}{ Group 3} & Group 1 & 0.0002 & $<0.0001$ & 0.83 & 0.58 & 0.58 & 0.43 & 0.98 & 0.54 \\
\hline & Group 2 & 0.19 & 0.013 & 0.99 & 0.99 & 0.99 & 0.99 & 0.99 & 0.99 \\
\hline & Group 4 & 0.44 & 0.57 & 0.99 & 0.97 & 0.97 & 0.58 & 0.99 & 0.98 \\
\hline \multirow[t]{4}{*}{ Group 4} & Group 1 & $<0.0001$ & $<0.0001$ & 0.76 & 0.27 & 0.24 & 0.01 & 0.96 & 0.12 \\
\hline & Group 2 & 0.009 & 0.001 & 0.99 & 0.99 & 0.99 & 0.73 & 0.99 & 0.98 \\
\hline & Group 3 & 0.44 & 0.57 & 0.99 & 0.97 & 0.97 & 0.58 & 0.99 & 0.98 \\
\hline & & \multicolumn{8}{|c|}{ P value } \\
\hline
\end{tabular}

P value < 0.05 is significant. Group1: Diabetic. Group 2: Diabetic + plasma. Group 3: Diabetic + Gallic acid and group 4: Diabetic + Gallic acid + plasma. GR, glutathione reductase; PON, paraoxonase; LPL, lipoprotein lipase; IL-2, Interluekine-2; IL-13, Interluekine-13; NF-кB, nuclear factor kappa-light-chain-enhancer of activated B cells

\section{DISCUSSION}

Our aim in this evaluation was the serum sample of people with diabetes under the influence of gallic acid and cold plasma. In this study, we evaluated the synergistic effect of gallic acid and cold plasma on oxidative stress and inflammation in diabetic patients. In our previous study, we reported the effect of cold plasma on antioxidant enzymes and minerals [23]. The result revealed that some antioxidant enzymes (such as GR, PON, and LPL), inflammatory factors (including IL-2, IL-13, and NF-KB), and biochemical factors (such as glucose and $\mathrm{H}_{2} \mathrm{O}_{2}$ ) were also present in people with diabetes and the samples were compared with healthy individuals.

A diet based on functional foods has been studied in the management of type $2 \mathrm{DM}$ as a novel dietary approach [24]. The anti-diabetic effects of gallic acid were investigated in several studies. Gallic acid is known as an adaptable scavenger with the capability of rapidly detoxifying reactive nitrogen and oxygen species via electron transfer [25]. Scholarly literature, has reported that after the administration of natural foods containing gallic acid to experimental animals, antioxidant effects were observed in different tissues such as the stomach and lung [26-27]. The antioxidant property of gallic acid has been reported in a diabetic rat model [28].

In addition, gallic acid has been observed to exhibit anti-inflammatory effects via suppression of pro-inflammatory cytokines and chemokines [29]. It is well-known that a common pathway of severe inflammation is triggered by NF-kB activation [30]. It 
can be considered that gallic acid may suppress NF-kB activation as a consequence of blocking TNF $\alpha$-induced activation of NF-KB.

The anti-hyperlipidemic and anti-diabetic properties of gallic acid on diabetic rats were investigated by Yigitturk et al [28]. According to the results, the treatment of diabetic rats with gallic acid leads to an increase in the concentration of antioxidant enzymes, including SOD and CAT. A decrease in lipid hydroperoxides was also observed in treated rats compared to untreated rats. Moreover, in several studies, the increased levels of GR, PON, and LPL activities due to supplementation of gallic acid were reported, which is in line with our results [31-33].

In a review article, Yang et al. found that gallic acid has a protective effect against oxidative stress. Gallic acid exerts this effect with its antioxidant, immune system modulating, and cellular protective properties (34).

The effect of gallic acid on insulin concentration and plasma glucose in diabetic rats was studied by Gandhi et al [35]. They stated that the administration of gallic acid $(20 \mathrm{mg} / \mathrm{kg})$ to diabetic rats resulted in significant $(P$ value $<0.05)$ restoration of changes in the level of insulin resistance to normalcy when compared with diabetic control rats. Also, they reported that gallic acid $(20 \mathrm{mg} / \mathrm{kg})$ supplemented diabetic rats showed a significant ( $P$ value $<0.05$ ) clearance of glucose level compared to diabetic control rats.

On the other hand, a study by Rezaeinezhad et al. showed that plasma treatment can detoxify the oxidative stress in diabetic mice through modification of glycated enzymes [22]. Moreover, they reported that plasma can regulate inflammatory cytokine secretion, improve insulin performance, and decrease the blood glucose level of diabetic mice. Thus, the results of our study, including the regulation of oxidative stress (decrease in $\mathrm{H}_{2} \mathrm{O}_{2}$ content and increase in activity of antioxidant enzymes), the decrease of inflammatory cytokines, and the decrease of glucose level were inconsistent with the results of the Rezaeinezhad et al. study.

In the present study, the results of treated samples with gallic acid and treated samples with gallic acid under plasma exposure were significant. It can be said that the use of cold plasma in addition to gallic acid treatment intensifies the activity of the antioxidant enzyme and thereby leads to more of a decrease in $\mathrm{H}_{2} \mathrm{O}_{2}$ content. Also, the results showed that utilizing both treatments improved the regulation of inflammatory cytokines.

In our previous articles and studies on the effects of lasers and plasma on oxidative stress, inflammation, and minerals [22-23, 36-37], we have seen changes in the levels of oxidants as well as H2O2 (a type of free radical). Furthermore, we know that both of them are involved in oxidation and reduction changes (redox process). In other words, oxidants and free radicals are involved in electron loss and capture, and probably because of this, electron beams that hit electrons can cause them to move. This displacement can affect electron capture and loss in the in vivo environment and during the redox process. In this study, this effect of CAP was considered and more studies are needed to accurately follow the effect of CAP according to the theory of redox process.

\section{CONCLUSION}

DM and the lack of control and management of this disease are associated with irreversible consequences. With the increase of blood glucose, inflammatory and oxidant factors also increase in the blood. These factors have deleterious effects and play a role in the pathology of DM. In conclusion, the results of the study 
showed that cold plasma treatment along with gallic acid supplementation can have a synergistic effect on the regulation of oxidative stress and inflammatory cytokine secretion in type 2 DM.

List of abbreviations: CAP: cold atmospheric plasma, APPJ: atmospheric pressure plasma jet, DM: diabetes mellitus, WHO: World Health Organization, HbA1c: glycated hemoglobin, ROS: Reactive oxygen species, $\mathrm{H}_{2} \mathrm{O}_{2}$ : hydrogen peroxide, IL-2: interleukin 2, IL-13: interleukin 13, GR: glutathione reductase, ELISA: enzyme-linked immunosorbent assay, NF-кB: nuclear factor kappa-light-chain-enhancer of activated B cells, PON: paraoxonase, LPL: lipoprotein lipase

Acknowledgments: The authors of this paper sincerely acknowledge the staff at Laser and Plasma Research Institute, Shahid Beheshti University.

Competing interests: The authors declare that there is no conflict of interest.

Author's contributions: The authors confirm contributions to the paper are as follows: DM participated in the study design and the article edition. $H G, A R$, and FJ performed experiments and treatment of samples with cold plasma by atmospheric pressure plasma jet device; MRA participated in the writing and analysis of the results; ASM assisted in experiments; HM contributed to the original idea of the paper, doing the experimental work and data collection. All authors read and approved the final version before its submission.

Human and animal studies: This article contains human studies. All of which were consented.

\section{REFERENCES}

1. Asgharzadeh F, Tanomand A, Ashoori MR, Asgharzadeh A, Zarghami N: Investigating the effects of Lactobacillus casei on some biochemical parameters in diabetic mice. J Evdocrinol Metabol Diabetes S AF 2017, 22 (3):47-50.

2. Nyaga DM, Vickers MH, Jefferies C, Perry JK, O'Sullivan JM: The genetic architecture of type 1 diabetes mellitus. Mol Cell Endocrinol 2018, 477:70-80.

3. Hussain, A., B. Claussen, A. Ramachandran, and R. Williams: Prevention of type 2 diabetes: a review. Diabetes Res Clin Pract 2007, 76 (3):317-326.

4. Bellou V, Belbasis L, Tzoulaki I, Evangelou E: Risk factors for type 2 diabetes mellitus: an exposure-wide umbrella review of meta-analyses. PloS one 2018, 13 (3):e0194127.

5. Ghafarian-Alipour F, Ziaee S, Ashoori MR, Zakeri MS, Boroumand MA, Aghamohammadzadeh $\mathrm{N}$, et al.: Association between FTO gene polymorphisms and type 2 diabetes mellitus, serum levels of apelin and androgen hormones among Iranian obese women. Gene 2018, 641:361-366.

6. Gulcin i: Antioxidants and antioxidant methods: An updated overview. Arch Toxicol 2020, 94 (3):651-715.

7. Panahi Y, Khalili N, Sahebi E, Namazi S, Karimian MS, Majeed M, et al.: Antioxidant effects of curcuminoids in patients with type 2 diabetes mellitus: a randomized controlled trial. Inflammopharmacology 2017, 25 (1):2531.

8. Alkhatib A, Tsang C, Tiss A, Bahorun T, Arefanian H, Barake $\mathrm{R}$, et al.: Functional foods and lifestyle approaches for diabetes prevention and management. Nutrients 2017, 9 (12):1310.

9. Konstantinidi $M$ and Koutelidakis $A E$ : Functional foods and bioactive compounds: A review of its possible role on weight management and obesity's metabolic consequences. Medicines 2019, 6 (3):94.

10. Kahkeshani N, Farzaei F, Fotouhi M, Alavi SS, Bahramsoltani R, Naseri R, et al.: Pharmacological effects of gallic acid in health and diseases: A mechanistic review. Iran J Basic Med Sci 2019, 22 (3):225.

11. Ferk F, Kundi M, Brath H, Szekeres T, Al-Serori H, Mišík M, et al.: Gallic acid improves health-associated biochemical parameters and prevents oxidative damage of DNA in type 2 diabetes patients: Results of a placebo-controlled pilot study. Mol Nutr Food Res 2018, 62 (4):1700482. 
12. Chakraborty A, Ferk F, Simić $T$, Brantner A, Dušinská M, Kundi $M$, et al.: DNA-protective effects of sumach (Rhus coriaria L.), a common spice: results of human and animal studies. Mutat Res 2009, 661 (1-2):10-17.

13. Bak EJ, Kim J, Jang S, Woo GH, Yoon HG, Yoo YJ, et al.: Gallic acid improves glucose tolerance and triglyceride concentration in diet-induced obesity mice. Scand J Clin Lab Invest 2013, 73 (8):607-614.

14. Punithavathi V, Stanely Mainzen Prince P, Kumar M, Selvakumari C: Protective effects of gallic acid on hepatic lipid peroxide metabolism, glycoprotein components and lipids in streptozotocin-induced type II diabetic wistar rats. J Biochem Mol Toxicol 2011, 25 (2):68-76.

15. Liu D, Zhang $Y, X u M$, Chen $H$, Lu X, Ostrikov K: Cold atmospheric pressure plasmas in dermatology: Sources, reactive agents, and therapeutic effects. Plasma Process Polym 2020, 17 (4):1900218.

16. Bernhardt $T$, Semmler $M L$, Schäfer $M$, Bekeschus $S$, Emmert S, Boeckmann L: Plasma medicine: Applications of cold atmospheric pressure plasma in dermatology. Oxid Med Cell Longev 2019, 2019

17. Xiong Z: Cold atmospheric pressure plasmas (CAPs) for skin wound healing. Plasma Medicine-Concepts and Clinical Applications; Intechopen: London, UK. Vol. 1. 2018, 121133.

18. Semmler ML, Bekeschus S, Schäfer M, Bernhardt T, Fischer T, Witzke K, et al.: Molecular mechanisms of the efficacy of cold atmospheric pressure plasma (cap) in cancer treatment. Cancers 2020, 12 (2):269.

19. Lima AL, Illing T, Schliemann S, Elsner P: Cutaneous manifestations of diabetes mellitus: a review. Am J Clin Dermatol 2017, 18 (4):541-553.

20. Mendes AL, Miot HA, Haddad Junior V: Diabetes mellitus and the skin. An Bras Dermatol 2017, 92 (1):8-20.

21. Han $\mathrm{Y}$, Cheng JH, Sun DW: Activities and conformation changes of food enzymes induced by cold plasma: A review. Crit Rev Food Sci Nutr 2019, 59 (5):794-811.

22. Rezaeinezhad A, Eslami $P$, Mirmiranpour $H$, Ghomi H: The effect of cold atmospheric plasma on diabetes-induced enzyme glycation, oxidative stress, and inflammation; in vitro and in vivo. Sci Rep 2019, 9 (1):1-11.

23. Martirosyan D, Ghomi H, Ashoori MR, Rezaeinezhad A, Mirmiranpour $\mathrm{H}$ : The effect of cold plasma on antioxidant enzymes, minerals, and some of the levels of the biochemical parameters in the subjects with type 2 diabetes mellitus samples. Bioact Compd Health Dis 2021, 4 (2):14-24.

24. Mirmiran P, Bahadoran Z, Azizi F: Functional foods-based diet as a novel dietary approach for management of type 2 diabetes and its complications: A review. World J Diabetes 2014, 5 (3):267.

25. Marino T, Galano A, Russo N: Radical scavenging ability of gallic acid toward $\mathrm{OH}$ and $\mathrm{OOH}$ radicals. Reaction mechanism and rate constants from the density functional theory. J Phys Chem B 2014, 118 (35):10380-10389.

26. Arora $\mathrm{P}$, Ansari S, Anjum V, Mathur R, Ahmad S: Investigation of anti-asthmatic potential of Kanakasava in ovalbumin-induced bronchial asthma and airway inflammation in rats. J Ethnopharmacol 2017, 197 242249.

27. Tamboli FA, More HN: Evaluation of antiulcer and antioxidant activity of Barleria gibsoni Dalz. leaves. Pharmacognosy Res 2016, 8 (4):226.

28. Yigitturk G, Acara AC, Erbas O, Oltulu F, Yavasoglu NUK, Uysal A, et al.: The antioxidant role of agomelatine and gallic acid on oxidative stress in STZ induced type I diabetic rat testes. Biomed Pharmacother 2017, 87 240-246.

29. Morais MC, Luqman S, Kondratyuk TP, Petronio MS, Regasini LO, Silva DH, et al.: Suppression of TNF- $\alpha$ induced NFKB activity by gallic acid and its semi-synthetic esters: possible role in cancer chemoprevention. Nat Prod Res 2010, 24 (18):1758-1765.

30. Meffert MK, Chang JM, Wiltgen BJ, Fanselow MS, Baltimore D: NF-KB functions in synaptic signaling and behavior. Nat Neurosci 2003, 6 (10):1072-1078.

31. Giftson JS, Jayanthi S, Nalini N: Chemopreventive efficacy of gallic acid, an antioxidant and anticarcinogenic polyphenol, against 1, 2-dimethyl hydrazine induced rat colon carcinogenesis. Clin Drug Investig 2010, 28 (3):251259.

32. Kartkaya K, Oğlakçı A, Şentürk H, Bayramoğlu G, Canbek M, Kanbak G: Investigation of the possible protective role of gallic acid on paraoxanase and arylesterase activities in livers of rats with acute alcohol intoxication. Cell Biochem Funct 2013, 31 (3):208-213.

33. Shaik AH, Shaik SR, Daddam JR, Ali D, Manoharadas S, Arafah MW, et al.: Maslinic acid and gallic acid protective efficacy on lipids, lipoproteins and lipid metabolizing enzymes against isoproterenol administered 
cardiotoxicity: An in vivo and in silico molecular docking evidences. J King Saud Univ Sci 2021, 33 (1):101230.

34. Yang $\mathrm{K}$, Zhang L, Liao $\mathrm{P}$, Xiao $Z$, Zhang $\mathrm{F}$, Sindaye $\mathrm{D}$, et al.: Impact of gallic acid on gut health: Focus on the gut microbiome, immune response, and mechanisms of action. Front Immunol 2020, 11:2231.

35. Gandhi GR, Jothi G, Antony PJ, Balakrishna K, Paulraj MG, Ignacimuthu S, et al.: Gallic acid attenuates high-fat diet fed-streptozotocin-induced insulin resistance via partial agonism of PPARY in experimental type 2 diabetic rats and enhances glucose uptake through translocation and activation of GLUT4 in PI3K/p-Akt signaling pathway. Eur J Pharmacol 2014, 745: 201-216.

36. Martirosyan D, Ashoori MR, Mirmiranpour H: The effect of low level-laser irradiation on antioxidant enzymes and mineral levels in serum of patients with type 2 diabetes mellitus. Bioact Compd Health Dis 2020, 3 (5): 82-89.

37. Martirosyan D, Mirmiranpour H, Ashoori MR: Synergistic effect of laser irradiation and cinnamic acid as a functional food on oxidative stress in type 2 diabetes mellitus. Bioact Compd Health Dis 2020, 3 (9):154-165. 